\title{
Functional turnover and community assemblage during tropical forest succession
}

\author{
V. Marcilio-Silva1 ${ }^{\text {, V. D. Pillar }}{ }^{2}$ and M. C. M. Marques ${ }^{1,3}$ \\ ${ }^{1}$ Laboratório de Ecologia Vegetal, SCB, Universidade Federal do Paraná, Curitiba, PR, Brazil \\ ${ }^{2}$ Laboratório de Ecologia Quantitativa, Departamento de Ecologia, IB, Universidade Federal do Rio Grande do Sul, \\ Porto Alegre, RS, Brazil \\ ${ }^{3}$ Corresponding author: viniciuschms@gmail.com
}

Keywords: Community assembly, Environmental filtering, Functional traits, Trait convergence, Trait divergence, Tropical forest.

\begin{abstract}
Changes in species composition during the succession of ecological communities potentially reflect the differential effects of environmental filters and limiting similarity on structuring communities. As ecological succession can represent community assembly in action, understanding how successional time affects the functional and phylogenetic structure of communities can reveal the influence of different factors on the assembly process. We analysed functional patterns of multiple traits related to the succession of tropical forests to answer if there are trait convergence and/or divergence with regeneration age, and if functional and phylogenetic diversity can be predicted by forest age. We compiled checklists from studies of 23 successional forests in Brazilian Atlantic Forest, ranging from 4 to 120 years old. We also compiled functional traits for a total of 355 species. We analysed the data by a method that includes scaling-up trait-based data to the community level and matrix correlations of multiple traits. We built linear models to show the relationship between each trait and diversity (taxonomic, functional and phylogenetic) with successional time. We found no phylogenetic signal at the species pool and metacommunity levels, but significant trait divergence (tree guild, leaf slenderness, leaf area, pollination entomophilous generalist and pollination by vertebrate) and trait convergence (arboreal habitus, tree guild, leaf compoundness, pollination entomophilous generalist) patterns related to the successional gradient. Also, functional diversity increased during succession, with a significant increase in leaf slenderness and zoochoric dispersal and decrease in tree guild. Phylogenetic diversity also increased along the successional gradient. We found that the communities in the studied successional gradient are structured by both environmental (measured by trait convergence) and biotic (measured by trait divergence) filtering. The species turnover and diversification at taxonomic level are followed by well-defined patterns of trait turnover, revealing that community assembly is constrained by environmental filters at the beginning and by limiting similarity at the advanced stages of the succession.
\end{abstract}

Nomenclature: A.P.G. III (2009).

Abbreviations: CM-Community Mean, TCAP-Trait Convergence Assembly Pattern, TDAP-Trait Divergence Assembly Pattern.

\section{Introduction}

The ecological succession is one of the oldest ecological theories (Clements 1916), but only recently has been recognized as an important theoretical framework for understanding the community assembly process (Meiners et al. 2015). The mechanistic processes determining species turnover along the time provide insights of how deterministic and stochastic events structure the community (Lebrija-Trejos et al. 2010, Swenson 2013). Specifically, by focusing on functional traits and phylogenetic constraints, successional studies can directly address the structural and historical processes determining community assembly (Götzenberger et al. 2011, Swenson 2013, Meiners et al. 2015). Thus, integrating species and traits turnover along the successional time can increase our understanding of how communities are assembled.
The secondary succession can be understood as a time gradient where sets of plant species are gradually replaced leading to changes in the environmental conditions. For example, in tropical forests, as time after disturbance increases, habitats progressively change from dry and hot to more humid and shaded (Bazzaz and Pickett 1980, Guariguata and Ostertag 2001). Gradients such as these are promising systems for the assessment of trait convergence and divergence patterns and for revealing assembly rules or constraints that can be useful to predict community structure (Weiher and Keddy 1999). In this context, the environment characteristics of a given site can act as abiotic filter and might lead to increase similarity in traits (i.e. trait convergence) among species of this community (Díaz et al. 1998, Pillar et al. 2009). Also, the coexistence of species should be restricted by the similarity in their traits, consequently leading to divergence 
in traits between co-occurring species, reducing negative biotic interactions (MacArthur and Levins 1967, Mayfield and Levine 2010). The species turnover among communities along succession can reveal both trait convergence and divergence patterns (Pillar et al. 2009): a trait convergence pattern is identified when communities with similar age (time after disturbance) contain species with similar traits and the variation in these traits is related to the successional time; a trait divergence pattern is identified when, regardless of the communities being compound by species with dissimilar traits, the turnover in trait-based community components is related to the successional time.

Studies of community assembly during the successional process revealed patterns of plant trait turnover in the successional gradient. In general, these studies show that plant traits individually move from a less variable state (trait convergence) to a more variable state (trait divergence) during the succession, as a response of change in environmental filtering and competition (Campetella et al. 2011, Lohbeck et al. 2012, Purschke et al. 2013, Bhaskar et al. 2014). This convergenceto-divergence pattern has been supported generally by analysis of the relative variation in a single trait along the time, and considering separately the convergence and divergence patterns. This approach can show the relations between the community assembly process and the functional traits by analyzing the patterns of change in each trait throughout the successional time (Herben and Goldberg 2014). However, this single-trait correlation ignores possible synergies between traits. This synergy is expected as all traits are expressed at the same time by organisms, but with different values and with different correlation between the traits (Herben et al. 2012, Gerhold et al. 2015). As traits are often part of more complex syndromes involving trade-offs and synergies (Herben et al. 2012), a multivariate analysis of traits patterns can go further into the understanding of the community assembly process. Focusing trait convergence and divergence separately is not enough to understand the whole process in the community assembly, as one must also consider possible interactions between them (Pillar et al. 2009).

The trait patterns may also reflect the effects of phylogenetic structure on community assembly (Kembel and Hubbell 2006). Biogeographic and macro-evolutionary processes determining the regional species pool can constrain the variation of the functional traits within communities composed by species from this pool (Webb et al. 2002, Cavender-Bares et al. 2009). Furthermore, the niche conservatism expectation argues that the species' ecological niches and the niche-related traits tend to be conserved between ancestors and descendants (Peterson 2011) leading to an expectation of phylogenetic signal at species' niches and traits. Thus, it is expected that communities composed by phylogenetically closely related species presents more phenotypic similarities with each other than communities with distantly related species (Blomberg and Garland 2002), affecting the trait convergence and divergence patterns. Detecting phylogenetic signal in the traits at the pool or metacommunity levels can be an important tool to understand community assembly during succession.
The functional and phylogenetic diversities can express the patterns of trait convergence and divergence, as well the phylogenetic structure of communities along gradients. There is a trend during the succession of increasing the taxonomic, functional and phylogenetic diversities (Letcher 2009, Lebrija-Trejos et al. 2010, Ding et al. 2012, Letcher et al. 2012, Lohbeck et al. 2012, Whitfeld et al. 2012).

However, studies linking functional and phylogenetic patterns during forest succession are still rare (but see Ding et al. 2012) even though they can potentially give more insight into the understanding of the community assembly process. Some studies have suggested that taxonomic diversity is a surrogate for functional diversity (Lohbeck et al. 2012). However, this assumption that taxonomic diversity is a good surrogate of functional and/or phylogenetic diversity can lead to mistakes because they are not always related (Prinzing et al. 2008, Devictor et al. 2010, Purschke et al. 2013, Herben and Goldberg 2014).

In this study, we analysed functional composition (community-proportional mean trait value; hereafter $\mathrm{CM}$ ) and diversity (Rao), and phylogenetic patterns related to the succession of tropical forests. We used a chronosequence of successional forests (4-120 years) occurring in the southern Brazilian Atlantic Forest as a model to explore the possible mechanistic factors affecting community assembly. We compiled species traits ( 8 traits, 355 species) and addressed phylogenetic structure of 23 communities aiming to understand how the species turnover occurs along the succession. First, we expect that multiple traits interact and are expressed in different ways along the successional gradient. We hypothesize that a set of traits related to plant survival in open habitats (e.g. shrub habitus, small leaves, abiotic pollination and seed dispersal) converges at the early-successional stages; on the other hand, we expect that the set of traits related to shaded and competitive habitats (e.g. arboreous habitus, larger leaves and biotic pollination and seed dispersal) diverges at the late-successional phases. We also expect that trait convergence and trait divergence patterns are shaped by the phylogeny leading the traits to show phylogenetic signal (at pool or metacommunity levels). Second, we hypothesize that trait convergence-to-divergence pattern in succession is expressed by increasing taxonomic, functional, and phylogenetic diversities. However, considering that independent processes can determine these diversities, we expect that the taxonomic, functional, and phylogenetic diversities are not related, or are barely related.

\section{Methods}

\section{Study area}

The Atlantic Forest [Floresta Atlântica], is distributed throughout almost the entire Brazilian Atlantic coast and, due to differences in latitude and historical processes, is highly variable in environmental terms throughout its range (Oliveira-Filho and Fontes 2000, Scarano 2002, Marques et al. 2011). We restricted the study to the southern portion of 
Dense Rain Forest (one of the Atlantic Forest types), which encompasses the states of Rio de Janeiro, São Paulo, Paraná and Santa Catarina, and represents one of three climatic and biogeographic regions (North, Central and South Blocks) of the Brazilian Atlantic Forest (Oliveira-Filho and Fontes 2000). The Atlantic Forest in this region is fragmented with patches of undisturbed forest located mainly on steep slopes (Ribeiro et al. 2009) and remaining fragments of secondary forests on sites that were used mostly for slash-and-burn agriculture during the last two centuries which were eventually abandoned (Liebsch et al. 2008). Previous studies in this region show a large interconnection among plant assemblies, reflecting the historical connection among them (Liebsch et al. 2008, Marques et al. 2011, Duarte et al. 2014). By restricting our dataset to sites in this specific region (Southern Block) and forest type (Dense Forest) within the Atlantic Forest Biome, we assume that: (i) the sites are linked by dispersal of multiple, potentially interacting species (i.e. the dataset compounds a metacommunity); (ii) the sites are under similar environmental and anthropogenic conditions. Thus, we assumed that dispersal limitation is less relevant than the other processes structuring plant communities at this spatial scale.

We searched in 2010 in Google Scholar (https://scholar. google.com/) and physical libraries for papers and theses published, with no temporal restriction, with the following words: succession (OR chronosequence) AND Mata Atlântica (OR Atlantic Forest) AND floristics (OR phytosociology). We initially checked the research data for the information about site historical use and forest age. The search resulted in 23 sites (11 studies) that were well distributed throughout the region (Fig. S1). All the studied sites share a similar historical use: they were used for agriculture or pasture and then abandoned; successional processes occurred, resulting in the establishment of secondary forests. The forests were aged from 4 to 120 years of abandonment after disturbance (Fig. S1, Table S1).

We tested for data quality before considering the communities in these sites as a metacommunity. First, we checked for possible bias caused by climate in the region and there were no relationships (Spearman correlations, all $\mathrm{P}>0.05$ ) among sites' age and site climate variables (all variables available in http://www.worldclim.org/). Due to logistic limitations, we were not able to access the variation in the soil and in the underlying geology among sites. Nevertheless, we assumed that differences among sites at the given scale were primarily determined by the successional stage. We also tested if sampling size and spatial autocorrelation between communities caused some bias in results, performing a Mantel correlation (based on Pearson's product-moment correlation and 999 permutations) between sample size, site localization and diversity (taxonomic, functional and phylogenetic) (Table S2). As we found no correlations (all $\mathrm{P}>0.05$, Table S2) we assumed no bias in our results. Thus, after controlling these possible biases in our dataset, we assume that processes determining phylogenetic and functional diversities at the local scale are reflected in the analysis of trait patterns in the studied metacommunity.

\section{Species checklist and compilation of species traits}

The checklist comprised a total of 355 tree species and was corrected for synonyms and identification errors using the Plantminer website (Carvalho et al. 2010). Data on functional traits that were collected from herbarium or literature sources (Table S3) and using standardised measurements (Cornelissen et al. 2003) were scored for the complete list of woody species. The traits (and respective states) chosen were as follows: habitus (tree, shrub), tree guild (canopy, understory), leaf compoundness (compound, simple leaves), leaf slenderness (continuous variable estimated by leaf length/ leaf width), leaf area (continuous variable estimated by the ellipse area $=\pi \times[($ leaf length $/ 2) \times($ leaf width/2) $])$, pollination syndrome (entomophilous generalist, entomophilous specialist, vertebrate), and dispersal syndrome (zoochory, non-zoochory) (Table 1). Although the number of traits available in literature for this set of species was limited, the selected traits are representative of main plant functions, such as plant growth, light optimization, and reproduction (Table 1). The leaf traits (leaf compoundness, leaf slenderness and leaf area) were obtained from general species' descriptions and the reproductive traits (pollination and dispersal syndromes) were obtained from specific regional studies (Table S2). For some species (23\%), additional morphometric data were also obtained using material from the UPCB herbarium and digital sources, such as the Digital Flora of Rio Grande do Sul (http://www.ufrgs.br/fitoecologia/florars) and JSTOR (Journal Storage) Plant Science (http:// http://plants.jstor. org/).

\section{Phylogeny}

We obtained the phylogenetic relationships among the 355 taxa using Phylomatic based on mega tree R20120829 (available at https://github.com/camwebb/tree-of-trees/blob/ master/megatrees/R20120829.new), which was constructed based on the phylogenetic relationships proposed by APGIII (2009). The method in question provides a useful measure to evaluate plant phylogeny (see Webb 2000, Webb et al. 2002, Pillar and Duarte 2010).

A qualitative matrix was generated for all species of examined communities. Based on APG III (2009), these species were described by the genus, family and clade of higher monophyletic groups (e.g., Eudicots, Magnoliophyta) (Webb et al. 2008). Tree branch lengths were calibrated using clade age estimates provided by Bell et al. (2010). Using the software PHYLOCOM, the similarities were then calculated between pairs of species to build the matrix of species phylogeny $\mathrm{S}_{\mathrm{F}}$ (ranging from 0 to 1 ).

\section{Analysis}

For both single and multiple traits analysis, Ricotta and Moretti (2011) stressed the benefits of using a framework that integrates the community functional composition and the functional diversity (Rao's coefficient; Botta-Dukát 2005) to access the convergence and divergence assembly pat- 
Table 1. Plant traits used for measures of functional diversity. For the analysis, pollination syndromes were transformed into as many binary traits as observed states (see methods).

\begin{tabular}{|c|c|c|}
\hline Traits & Functional role & Scale / States \\
\hline \multicolumn{3}{|l|}{ Growth } \\
\hline Arboreal habitus & Light and nutrient capture efficiency & Binary (1: tree, 0 : shrub) \\
\hline Tree guild & Light and nutrient capture efficiency & Binary (1: canopy, 0 : understory) \\
\hline \multicolumn{3}{|l|}{ Leaf function } \\
\hline Leaf compoundness & Light capture investment (structure) & Binary (1: compound, 0 : else) \\
\hline Leaf slenderness & Light capture efficiency (self-shedding) & Ratio scale (mm) \\
\hline Leaf area & Light capture efficiency, water balance & Ratio scale $\left(\mathrm{mm}^{2}\right)$ \\
\hline \multicolumn{3}{|l|}{ Reproduction } \\
\hline Pollination syndrome & Crossbreeding efficiency & \\
\hline Entomophilous generalist & & Binary (1: generalist, 0 : else) \\
\hline Entomophilous specialist & & Binary (1: specialist, 0 : else) \\
\hline Vertebrate & & Binary (1: vertebrate; 0 : else) \\
\hline Zoochoric dispersal syndrome & Spatial dispersion & Binary (1: zoochory, 0 : else) \\
\hline
\end{tabular}

terns. Despite the community functional composition and the functional diversity not being completely independent of each other, they represent different aspects of community structure (Ricotta and Moretti 2011). The community means reveal shifts in each single-trait value responding to the environmental filtering (Ricotta and Moretti 2011) and can also indicate convergence patterns, while the Rao's coefficient (Functional diversity index; Botta-Dukát 2005) measures the trait dispersion and can indicate both convergence and divergence patterns (Pillar and Duarte 2010).

To explore patterns of trait convergence and divergence in the metacommunity in a multivariate way we chose the analytical approach proposed by Pillar et al. (2009). This approach allows to discriminate trait-convergence and trait-divergence assembly patterns along ecological community gradients and is accurate to test the specific hypothesis to community processes (Pillar et al. 2009). Also, this framework simultaneously uses the community mean trait $(\mathrm{CM})$ and the dispersion (Rao) of the functional composition (Ricotta and Moretti 2011) to access trait patterns on community assembly (Pillar and Duarte 2010). The CM expresses the proportional mean trait values found among the species compounding a given community, and it is calculated similarly to the CWM (Garnier et al. 2004), but using an occurrence matrix (i.e. without abundance). The method used here consists of constructing matrices of communities (W), traits (B) and gradient (E) and of multiple matrix correlations allowing to find Trait Convergence Assembly Pattern (TCAP) and Trait Divergence Assembly Pattern (TDAP) that are related to environmental gradients (see the general analytical framework in Figure S2 a-c). When used in a successional gradient, this multivariate approach allows the detection of possible combinations of plant's traits related with abiotic and biotic filtering along the succession. A binary matrix (W) of presences/absences of
355 species in the 23 sites was generated describing the communities (for the purpose of analysis, each of the 23 sites was considered a community). In parallel, the trait data for species were arranged in another matrix (B), with binary variables or dummy variables (nominal multistate traits expanded into binary ones) (see Table 1). In addition, matrix (E) is defined by the community age (as the ecological variable), which was $\log$ transformed.

The analysis involved the definition of a matrix T of CMs by sites (Fig S2.b), and a matrix X of species by sites with the species' presences weighted by their trait similarities (Fig. S2.c). Significant values of $\rho$ (TE) resulted from the correlation between matrices T and E (Fig. S2.b) and $\rho$ (XE.T), resulted from the correlation between matrices $\mathrm{X}$ and $\mathrm{E}$ (Fig. S2.c) with the removal of $T$, will indicate, respectively, the manifestation of trait convergence and trait divergence in the metacommunity. An optimization algorithm (Pillar and Sosinski 2003) was applied to select trait subsets maximizing the above-mentioned correlations. The statistical significance of the correlations was tested by permutation against a null model of independence between the species' occurrences and their traits. See further details in Pillar et al. (2009).

The analysis of phylogenetically structured patterns followed the method described above, but also included the matrix $\left(\mathrm{S}_{\mathrm{F}}\right)$ with phylogenetic similarities between species computed after the topology of the phylogenetic tree of the 355 species (Pillar and Duarte 2010, Fig. S2 a). We assessed phylogenetic signal at the species pool level (PSS) by a matrix correlation $\rho(B F)=\rho\left(S_{F} ; S_{B}\right)$ between species phylogenetic similarities (already defined as matrix $\mathrm{S}_{\mathrm{F}}$ ) and species trait similarities (defined as matrix $S_{B}$ ). A high value for $\rho(B F)$ indicates that species with similar traits are also more phylogenetically similar. We also measured phylogenetic signal at the metacommunity level, $\rho(\mathrm{PT})$, calculated from the correla- 
Table 2. Trait-divergence and trait-convergence assembly patterns related to forest succession, and phylogenetic signal at the species pool level (PSS) and at metacommunity level related to traits maximising convergence $\left(\mathrm{PSM}_{\mathrm{T}}\right)$ and divergence $\left(\mathrm{PSM}_{\mathrm{X} . \mathrm{T}}\right)$. Results for combinations of traits that maximised, at the metacommunity level, the expression of trait divergence assembly pattern (TDAP) and trait convergence assembly pattern (TCAP) related to forest regeneration age. Significant P-values are in bold. See Table 1, for trait descriptions.

\begin{tabular}{lcc}
\hline & Maximizing divergence & Maximizing convergence \\
\hline Traits & $\begin{array}{l}\text { Tree guild, leaf slenderness, leaf area, enthomophilous } \\
\text { generalist pollination, vertebrate pollination }\end{array}$ & $\begin{array}{l}\text { Arboreal habitus, tree guild, leaf compound- } \\
\text { ness, enthomophilous generalist pollination }\end{array}$ \\
TCAP $[\rho(\mathrm{TE})]$ & $0.150(\mathrm{P}=0.306)$ & $\mathbf{0 . 5 0 1}(\mathbf{P}=\mathbf{0 . 0 0 1})$ \\
TDAP $[\rho(\mathrm{XE} . \mathrm{T})]$ & $\mathbf{0 . 4 7 8}(\mathbf{P}=\mathbf{0 . 0 0 4})$ & $-0.274(\mathrm{P}=0.980)$ \\
PSS $[\rho(\mathrm{FBF})]$ & $0.045(\mathrm{P}=0.139)$ & $-0.013(\mathrm{P}=0.603)$ \\
PSMT $[\rho(\mathrm{PT})]$ & $0.144(\mathrm{P}=0.836)$ & $0.224(\mathrm{P}=0.695)$ \\
PSMX.T $[\rho(\mathrm{PX} . \mathrm{T})]$ & $0.094(\mathrm{P}=0.855)$ & $-0.106(\mathrm{P}=0.067)$ \\
\hline
\end{tabular}

tion between matrix P (communities weighted by their species phylogenetic similarities) and matrix T (Pillar and Duarte 2010, Fig. S2 d). In this case, phylogenetic signal related to trait convergence (PSMT) was measured by matrix correlation $\rho(\mathrm{PT})$, and phylogenetic signal related to trait divergence (PSMX.T) was measured by partial matrix correlation $\rho$ (PX.T) of P and X with the removal of T (Pillar and Duarte 2010). The significance of the correlations was tested against null models (Pillar and Duarte 2010). All correlations and partial correlations were tested by Mantel test. In all analyses, the null models that were used retained most of the real data structures except for the one that is to be tested.

Each community's functional diversity was measured by Rao quadratic entropy (Botta-Dukát 2005), considering different sets of traits for the computation of species' distances: all traits evaluated (RAO all traits), traits that maximised convergence (RAO TCAP) and divergence (RAO TDAP). For simplifying comparisons, we used the same function to compute phylogenetic diversity (RAO P) based on phylogenetic dissimilarities. Functional and phylogenetic analyses were performed with software SYNCSA (Pillar et al. 2009).

We built linear models of functional and phylogenetic Rao diversity and richness (in log) on forest regeneration age. Additionally, we built linear models of CMs (from matrix T) using forest regeneration age (in $\log$ ) as the predictor.

\section{Results}

\section{TCAP and TDAP patterns}

The following trait subset maximized the expression of trait divergence assembly patterns (TDAP) related to forest regeneration age: tree guild, leaf slenderness, leaf area, pollination by entomophilous generalist and pollination by vertebrates, which was indicated by a significant matrix correlation $\rho(\mathrm{XE} . \mathrm{T})=0.478(\mathrm{P}=0.004$, Table 2$)$. The following trait subset maximised trait convergence assembly patterns (TCAP) related to forest regeneration age: arboreal habitus, tree guild, leaf compoundness and pollination by entomophil- ous generalist, with a significant correlation $\rho(\mathrm{TE})=0.501$ $(\mathrm{P}=0.001$, Table 2$)$. Tree guild and pollination by entomophilous generalist are traits maximising both TDAP and TCAP related to succession age. No significant phylogenetic signal at the species pool level (PSS) or metacommunity level (PSMT and PSMX.T) was found (Table 2).

Further examination of variation in CM (Fig. 1) showed that increasing forest regeneration age was significantly related to increasing leaf slenderness $\left(r^{2}=0.25, P=0.008\right.$, Fig. 1d) and proportion of zoochoric species $\left(\mathrm{r}^{2}=0.17, \mathrm{P}=0.02\right.$, Fig. $1 i)$, and to decreasing proportion of canopy species $\left(\mathrm{r}^{2}=0.50\right.$, $\mathrm{P}<0.001$, Fig. 1b). The remaining plant traits were not significantly related $(\mathrm{P}>0.05)$ to forest regeneration age.

\section{Diversity patterns}

Functional diversity defined by traits maximizing convergence (RAO TCAP) and by traits maximizing divergence (RAO TDAP) increased with forest age $\left(\mathrm{r}^{2}=0.24, \mathrm{P}=0.01\right.$, Fig. $2 b$, and $\mathrm{r}^{2}=0.16, \mathrm{P}=0.038$, Fig. $2 \mathrm{c}$ ), despite functional diversity defined with all traits being unrelated to forest age $(\mathrm{P}>0.05$, Fig. 2a). Additionally, phylogenetic diversity (RAO $\mathrm{P}, \mathrm{r}^{2}=0.27, \mathrm{P}=0.006$, Fig. $2 \mathrm{~d}$ ), and log-taxonomic diversity (log-richness; $r^{2}=0.43, P<0.001$, Fig. 2e) significantly increased with forest regeneration age. Despite the increase in functional and phylogenetic diversity during succession, no relationships were found between RAO P and RAO TCAP $(\mathrm{P}>0.05)$, or between RAO $\mathrm{P}$ and RAO TDAP $(\mathrm{P}>0.05)$, suggesting that independent processes operate towards the definition of phylogenetic and functional diversity.

\section{Discussion}

\section{TCAP and TDAP patterns}

A set of traits related to plant growth (arboreal habitus and tree guild), leaf function (leaf slenderness, leaf compoundness, and leaf area) and reproduction (entomophilous generalist pollination and pollination by vertebrates) was sig- 
nificantly related to divergence and convergence within plant communities, indicating that trait-based assembly rules drive community changes along the process of succession. The expression of TCAPs is related to the environmental filters that determine that species with similar traits are present in a community at a rate that is higher than by chance (Keddy 1992, Pillar and Duarte 2010). The traits maximising convergence in the gradient, i.e., arboreal habitus, tree guild, entomophilous generalist pollination, and leaf compoundness, are possibly filtered by the environment during succession. The convergence pattern is related to all the successional gradient, but we can assume the direction (early to later succession, or the opposite) in which this convergence pattern is occurring by looking at the functional diversity pattern of this set of traits, as the Rao index represents trait dispersion (Ricotta and Moretti 2011). As functional diversity of traits related to TCAP (RaoTCAP) increases with successional time (Fig 2b). the convergence is occurring from later to early succession; in other words, species in the early succession present smaller variation of this set of traits. It is possible that these traits are constrained by environmental filters (possibly higher temperature, lower air relative humidity) in early succession. Trait convergence associated with functional redundancy was also found in previous studies of succession (Fukami et al. 2005, Campetella et al. 2011, Lohbeck et al 2012) and is possibly a strong factor affecting plant assemblies at the beginning of the succession (Shooner et al. 2015).

In contrast to TCAP, the expression of TDAP reveals the similarity limitation that arises from interactions among cooccurring species (MacArthur and Levins 1967). In the studied successional gradient, the maximisation of divergence by the set of traits (tree guild, leaf slenderness, leaf area, entomophilous generalist pollination and pollination by vertebrates)
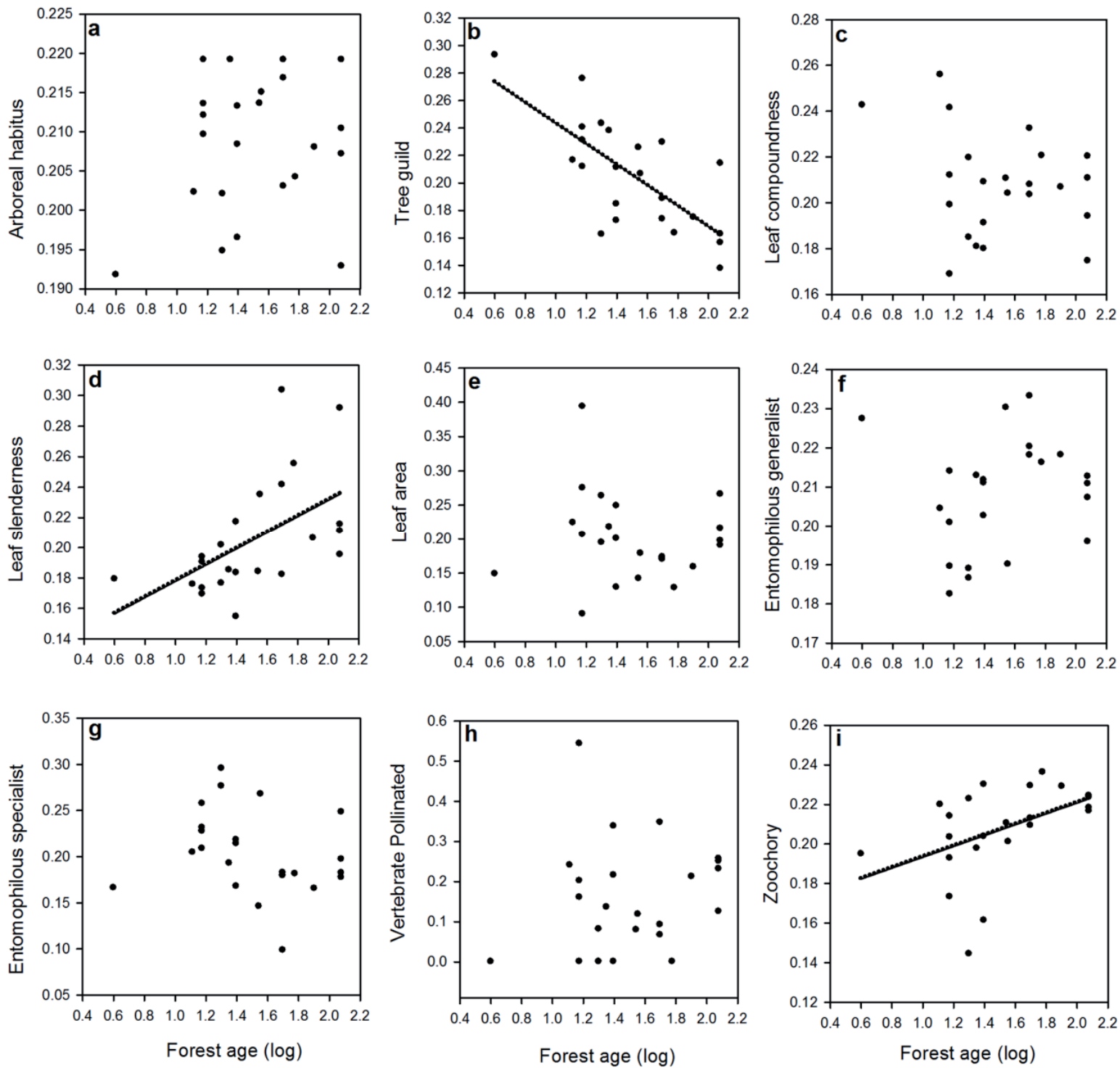

Figure 1. Relations between forest regeneration age and community-proportional mean trait values. a-b: growth traits; c-e: leaf function traits; $\mathbf{f}-\mathbf{i}$ : reproductive traits. Trait descriptions are in Table 2. 

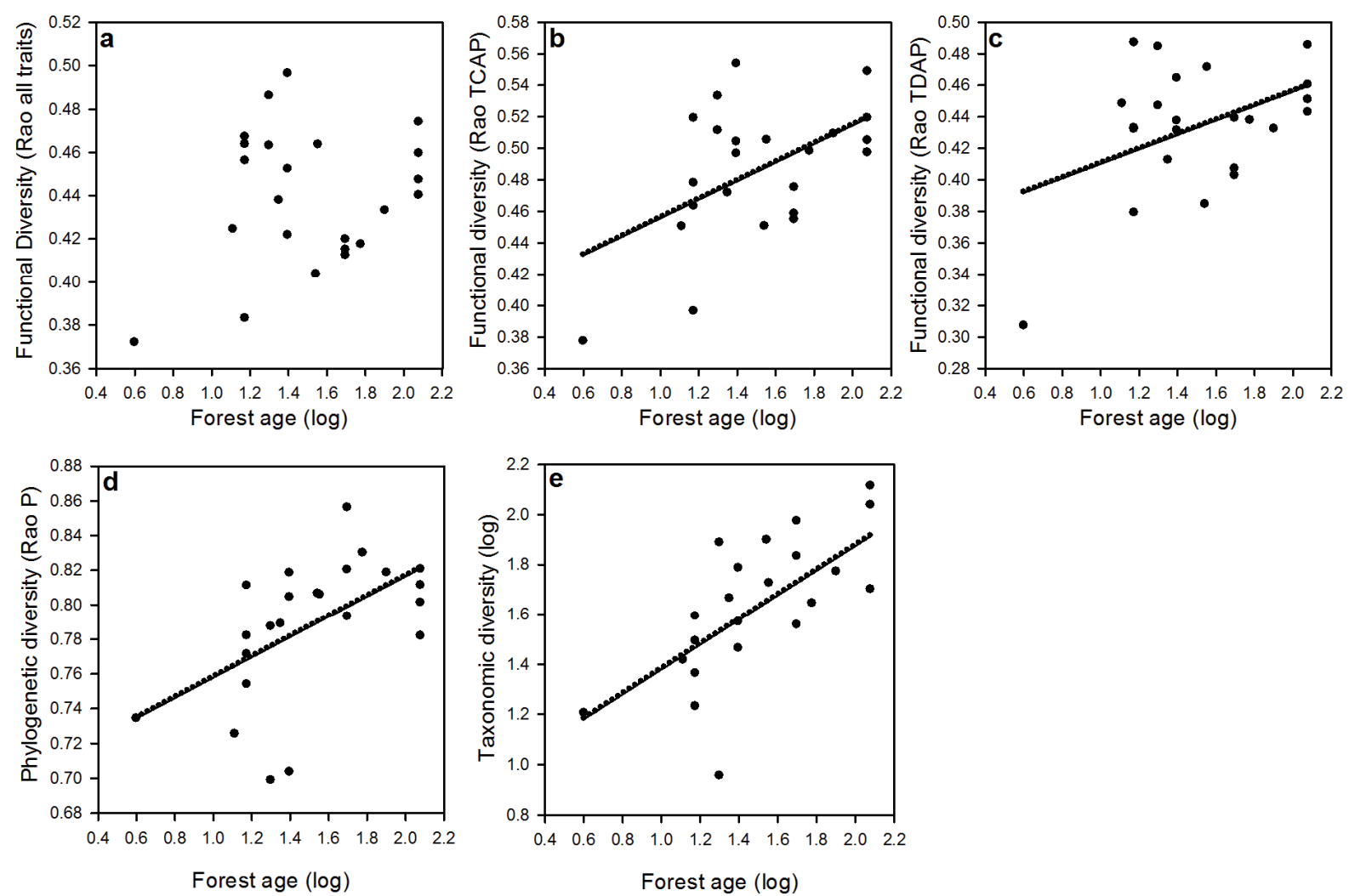

Figure 2. Relations between forest regeneration age and functional (a, b and $\mathbf{c}$ ) and phylogenetic (d) diversities (measured by Rao's quadratic entropy), and taxonomic diversity (e).

possibly results from species competition for light, space and pollinators. The decreasing effect of the environmental filters, associated with the increasing habitat heterogeneity along the succession, allows the co-occurrence of species that differ in its resource needs and utilization. In this situation, the species are more likely to avoid the similarity limitation in the advanced stages of succession, leading to higher functional diversity in these stages as also found by other successional studies (Campetella et al. 2011, Lohbeck et al. 2012, Purschke et al. 2013).

It is possible, through the present framework (Pillar et al. 2009), to detect the simultaneous occurrence of trait convergence and divergence in a same given trait, as it was detected in our data in the entomophilous generalist pollination and tree guild. This pattern is explained by a simultaneous variation in the trait along the successional time and among communities with similar age after disturbance. We found these traits to be constrained in communities at the early succession, leading to convergence patterns, and then they diversify among communities as succession proceeds, leading to divergence patterns. The entomophilous generalist pollination syndrome can facilitate the reproduction of plants in early successional stages. In these recently disturbed environments, the dependency of a more specialized pollination syndrome, that tends to appear late in succession, can lead to a worse plant performance. The proportion between tree and shrub species (tree guild) converges in the early succession and in- creasingly diverges as succession proceeds. This is probably linked to the biology of the early successional species. These are typically species with an early and abundant production of seeds with long-distance dispersal (Bazzaz and Pickett 1980). This set of characteristics constrains the number of tree and shrub species able to colonize initial stages, leading to a homogenisation of this relation (tree/shrub) among communities in the early succession.

\section{Phylogenetic signal}

The lack of phylogenetic signal at the species pool and metacommunity levels contradicts our primary expectations. There is a trend in community assembly studies to support the niche conservatism expectation (i.e. species ecological niches and niche-related traits tend to be conserved between ancestors and descendants; Peterson 2011), but counterexamples are building in ecological literature (Losos 2008, Mouquet et al. 2012, Purschke et al. 2013, Gerhold et al. 2015). This mismatch between traits and phylogeny can be attributed to different mechanisms (see Mouquet et al. 2012, Gerhold et al. 2015). In short, the study scale (Weiher et al. 2011) and/or set of traits can be too restrictive to reveal a phylogenetic signal, even if it existed; niche evolution rates can differ between lineages (Srivastara et al. 2012); and the occurrence of character displacement between coexisting related species (Lack 1942) can result in loss of correlation between phylogenetic 
distance and trait dissimilarity. Our results suggest that the traits under change (convergence/divergence) at the community level during the tropical forest succession are labile in the phylogeny.

\section{Functional composition turnover}

The relationship between the community mean traits and forest age revealed a significant increase in leaf slenderness and zoochory and decrease in tree guild during the succession. Leaf slenderness is a required trait in shaded sites for light capture and self-shading avoidance in the late phases of forest succession (Rozendaal et al. 2006, Lebrija-Trejos et al. 2010). It is possible that this trait also responds to other environmental variables that covariate with light availability during succession, such as air humidity and temperatures in understory (Bazzaz and Pickett 1980). Zoochory is a wellknown characteristic of mature forests (Guariguata and Ostertag 2001, Liebsch et al. 2008) and is associated with a high frugivorous activity in old-growth forests. Conversely, the decrease in the tree guild reflects the increase in forest stratification in old-growth forests, an important determinant of structural changes in forests during succession (Chazdon 2008). The other traits were not related to forest age (arboreal habitus, leaf compoundness, leaf area, entomophilous generalist and specialist pollination, vertebrate pollination). We expected an increment in the leaf area (Bazzaz and Pickett 1980), and in the proportion of specialist and vertebrate pollinations (Opler et al. 1980, Girão et al. 2007) during the succession. However, specialist and vertebrate pollinations were more frequent approximately in the middle of the successional gradient studied (forests with $15-50$ years). We also expected a decrease in the arboreal habitus (i.e. increased frequency of shrubs) as forests became older (Chazdon 2008), but large variations among sites resulted in no significant relationships. The absence of a relationship between frequency of leaf compoundness and forest age was also found for other wet tropical forests (Lohbeck et al. 2013), which suggests the occurrence of this trait is not strongly determined by successional gradient.

\section{Diversity patterns}

The increase in species richness (taxonomic diversity) was followed by an increase in functional and phylogenetic diversity during succession, in agreement with previous studies in tropical forests (Letcher et al. 2012, Lohbeck et al. 2012). Changes in the environment during succession lead to the creation of new habitats in which the water availability is stabilised in late-successional forests (Guariguata and Ostertag 2001). In these new microsites, functionally distinctive species find conditions suitable to the establishment, resulting in an increase in functional diversity (Lebrija-Trejos et al. 2010). It is possible that environmental filters are progressively more permissive to functional groups that were not present at the beginning of the succession. In the first stages of the succession, environmental filters act at a large scale in the community (Bazzaz and Pickett 1980); in the course of the succession, environmental filters act locally (for example, differences in water availability and light incidence among microsites) (Bazzaz and Pickett 1980). Late successional stages are more heterogeneous environments with variation in the degree of resource limitation and trade-offs in lifehistory may lead to coexistence (Mouquet et. al. 2002). The successional process studied here possibly reflects changes in multidimensional scales of the environmental filters, resulting in differences in the species interactions.

Functional (RAO TCAP or RAO TDAP) and phylogenetic diversities were not related to each other along the studied successional gradient, same as found for long-term succession in grasslands (Purschke et al. 2013), suggesting that independent processes operate towards the definition of these diversity indices. This result could be explained by a process where sets of species, phylogenetically independent and functionally distinct, are continually incorporated in the community along the succession. This corroborates the strong limitations of using the phylogenetic pattern as a proxy for the functional pattern in successional gradients (Purschke et al. 2013).

\section{Conclusions}

The analysis of the functional patterns in this tropical successional gradient suggests that the communities are mainly structured by environmental filtering (leading to trait convergence) in the early stages and by biotic filtering (leading to trait divergence) in the later stages of succession. The phylogenetic analysis reveals these convergent and divergent traits are not phylogenetically conserved. Different traits associated with plant growth, leaf function, and reproduction, can act in synergy enabling sets of plants to survive in the gradient from stressful to competitive habitats. Thus, plant assemblies along successional gradients are structured by mechanistic processes determining functional turnover throughout time. Despite the succession of tropical forests being marked by stochasticity (Chazdon 2008, Lebrija-Trejos et al. 2010), our study also reveals deterministic processes during the community assembly of tropical forests.

Acknowledgements: We thank D. Liebsch and R. Camargo for their contribution to dataset organization, all anonymous reviewers for comments on the manuscript, and to the Brazilian Education Council (CAPES) for the scholarship to V.M.S. This study was financially supported by the Brazilian Research Council (CNPq, Grant 577336/2008 8), which also supported M.C.M. Marques (Grant 229349/2013-7) and V. D. Pillar (Grant 306573/2009-1).

\section{References}

A.P.G. III. 2009. An update of the Angiosperm Phylogeny Group classification for the orders and families of flowering plants: APG III. Bot. J. Linn. Soc. 161: 105-121. 
Bazzaz, F.A., and S.T.A. Pickett. 1980. Physiological ecology of tropical succession: a comparative review. Annu. Rev. Ecol. Syst. 11: $287-310$.

Bell, C. D., D. E. Soltis and P.S. Soltis. 2010. The age and diversification of the angiosperms re-revisited. Am. J. Bot. 97: 1296-1303.

Bhaskar, R., T. E. Dawson and P. Balvanera. 2014. Community assembly and functional diversity along sucession post-management. Funct. Ecol. 28: 1256-1265.

Blomberg, S.P. and T. Garland. 2002. Tempo and mode in evolution: phylogenetic inertia, adaptation and comparative methods. $J$. Evol. Biol. 15: 899-910.

Botta-Dukát, Z. 2005. Rao's quadratic entropy as a measure of functional diversity based on multiple traits. J. Veg. Sci. 16: 533-540.

Campetella, G., Z. Botta-Dukát, C. Wellstein, R. Canullo, S. Gatto, S. Chelli, L. Mucina and S. Bartha. 2011. Patterns of plant traitenvironment relationships along a forest succession chronosequence. Agr. Ecosyst. Environ. 145: 38-48.

Carvalho, G.H., M.V. Cianciaruso and M.A. Batalha. 2010. Plantminer: A web tool for checking and gathering plant species taxonomic information. Environ. Modell. Softw. 25: 815-816.

Cavender-Bares, J., K.H. Kozak, P.V.A. Fine and S.W. Kembel. 2009. The merging of community ecology and phylogenetic biology. Ecol. Lett. 12, 693-715.

Chazdon: R.L. 2008. Chance and determinism in tropical forest succession. In: W.P. Carson and S.A. Schnitzer. (eds.), Tropical Forest Community Ecology. Wiley-Backwell, Oxford. pp. 384408.

Clements, F.E. 1916. Plant Succession: An Analysis of the Development of Vegetation. Carnegie Institution of Washington, Washington.

Cornelissen, J.H.C., S. Lavorel, E. Garnier, S. Díaz, N. Buchmann, D.E. Gurvich, P.B. Reich, H. ter Steege, H.D. Morgan, M.G.A van der Heijden, J.G. Pausas and H. Poorter. 2003. A handbook of protocols for standardised and easy measurement of plant functional traits worldwide. Aust. J. Bot. 51: 335-380.

Devictor, V., D. Mouillot, C. Meynard, F. Jiguet, W. Thuiller and N. Mouquet. 2010. Spatial mismatch and congruence between taxonomic, phylogenetic and functional diversity: the need for integrative conservation strategies in a changing world. Ecol. Lett. 13: 1030-1040.

Díaz, S., M. Cabido and F. Casanoves. 1998. Plant functional traits and environmental filters at the regional scale. J. Veg. Sci. 9: 113-122.

Ding, Y., R. Zang, S.G. Letcher, S. Liu, and F. He. 2012. Disturbance regime changes the trait distribution, phylogenetic structure and community assembly of tropical rain forests. Oikos 121: 12631270 .

Duarte, L.D.S., R.S. Bergamin, V. Marcilio-Silva, G.D.D.S. Seger and M.C.M. Marques. 2014. Phylobetadiversity among forest types in the Brazlian Atlantic forest complex. PLoS One 9: e105043.

Fukami, T., T.M. Bezemer, S.R. Mortimer, and W.H. Van der Putten. 2005. Species divergence and trait convergence in experimental plant community assembly. Ecol. Lett. 8: 1283-1290.

Garnier, E., J. Cortez, G. Billes, M.L. Navas, C. Roumet, M. Debussche, G. Laurent, A. Blanchard, D. Aubry, A. Bellmann, C. Neill and J.P. Toussaint. 2004. Plant functional markers capture ecosystem properties during secondary succession. Ecology 85: $2630-2637$.

Gerhold, P., J.F. Cahill Jr., M. Winter, I.V. Bartish and A. Prinzing. 2015. Phylogenetic patterns are not proxy of community assembly mechanisms (they are far better). Funct. Ecol. 29: 600-614.
Girão, L.C., A.V. Lopes, M. Tabarelli and E.M. Bruna. 2007. Changes in tree reproductive traits reduce functional diversity in a fragmented Atlantic forest landscape. PLOS ONE 2, e908.

Götzenberger L., F. de Bello, K.A. Bråthen, et al. 2011. Ecological assembly rules in plant communities-approaches, patterns and prospects. Biol. Rev. 87: 111-27.

Guariguata, M.R. and R. Ostertag. 2001. Neotropical secondary forest succession: changes in structural and functional characteristics. Forest Ecol. Manag. 148: 185-206.

Herben, T. and D.E. Goldberg. 2014. Community assembly by limiting similarity vs. competitive hierarchies: testing the consequences of dispersion of individual traits. J. Ecol. 102: 156-166.

Herben, T., Z. Novakova, J. Klimesova and L. Hrouda. 2012. Species traits and plant performance: functional trade-offs in a large set of species in a botanical garden. J. Ecol. 100: 1522-1533.

Keddy, P.A. 1992. Assembly and response rules: two goals for predictive community ecology. J. Veg. Sci. 3: 157-164.

Kembel, S. and S.P. Hubbell. 2006. The phylogenetic structure of a neotropical forest tree community. Ecology 87: 86-99.

Lack, D. 1942. Ecological features of the bird faunas of British smallislands. J. Anim. Ecol. 11: 9-36.

Lebrija-Trejos, E., E.A. Pérez-García, J.A. Meave, F. Bongers and L. Poorter. 2010. Functional traits and environmental filtering drive community assembly in a species- rich tropical system. Ecology 91: 386-398.

Letcher, S.G. 2009. Phylogenetic structure of angiosperm communities during tropical forest succession. P. Roy. Soc. Lond. B. Bio. 277: $97-104$

Letcher, S.G., R.L. Chazdon, A.C.S. Andrade,F. Bongers, M. van Breugel, B. Finegan, S.G. Laurance, R.C.G. Mesquita, M. Martínez-Ramos and G.B. Williamson. 2012. Phylogenetic community structure during succession: Evidence from three Neotropical forest sites. Perspect. Plant Ecol. Evol. Syst. 14: 79-87.

Liebsch, D., M.C.M Marques and R. Goldenberg. 2008. How long does the Atlantic Rain Forest take to recover after a disturbance? Changes in species composition and ecological features during secondary succession. Biol. Conserv. 141: 1717-1725.

Lohbeck, M., L. Poorter, H. Paz, L. Plac, M. van Breugel, M. Martínez-Ramos and F. Bongers. 2012. Functional diversity changes during tropical forest succession. Perspect. Plant Ecol. Evol. Syst. 14: 89-96.

Lohbeck, M., L. Poorter, E. Lebrija-Trejos, M. Martínez-Ramos, J.A. Meave, H. Paz, E.A. Pérez-García, E. Romero-Pérez, A. Tauro and F. Bongers. 2013. Successional changes in functional composition contrast for dry and wet tropical forest. Ecology 94: 1211-1216.

Losos, J.B. 2008. Phylogenetic niche conservatism, phylogenetic signal andthe relationship between phylogenetic relatedness and ecological similarity among species. Ecol. Lett. 11: 995-1003.

MacArthur, R. and R. Levins. 1967. The limiting similarity, convergence, and divergence of coexisting species. Am. Nat. 101: $377-385$.

Marques, M.C.M., M. Swaine and D. Liebsch. 2011. Diversity distribution and floristic differentiation of the coastal lowland vegetation: implications for the conservation of the Brazilian Atlantic Forest. Biodivers. Conserv. 20: 153-168.

Mayfield, M.M. and J.M. Levine. 2010. Opposing effects of competitive exclusion on the phylogenetic structure of communities. Ecol. Lett. 13: 1085-1093.

Meiners, S.J., M.W. Cadotte, J.D. Fridley, S.T.A. Pickett and L.R. Walker. 2015. Is successional research nearing its climax? New 
approaches for understanding dynamic communities. Funct. Ecol. 29: 154-164.

Mouquet, N., V. Devictor, C.N. Meynard,F. Munoz, L.F. Bersier, J. Chave, J. et al. 2012. Ecophylogenetics: advances and perspectives. Biol. Rev. 87: 769-785

Mouquet, J.L. Moore and M. Loreau. 2002. Plant species richness and community productivity: why the mechanism that promotes coexistence matters. Ecol. Lett. 5: 56-65.

Oliveira-Filho, A.T. and M.A.L. Fontes. 2000. Patterns of floristic differentiation among Atlantic forests in south-eastern Brazil, and the influence of climate. Biotropica 32: 793-810.

Opler, P.A., H.G. Baker and G.W. Frankie. 1980. Plant reproductive characteristics during secondary succession in neotropical lowland forest ecosystems. Biotropica 12: 40-46.

Peterson, A.T. 2011. Ecological niche conservatism: a time-structuredreview of evidence. J. Biogeogr. 38: 817-827.

Pillar, V.D. and L.D.S Duarte. 2010. A framework for metacommunity analysis of phylogenetic structure. Ecol. Lett. 13: 587-596.

Pillar, V.D., L.S. Duarte, E.E. Sosinski and F. Joner. 2009 Discriminating trait-convergence and trait-divergence assembly patterns in ecological community gradients. J. Veg. Sci. 20: 334-348.

Pillar, V.D.and E.E. Sosinski. 2003. An improved method for searching plant functional types by numerical analysis. J. Veg. Sci. 14: 323-332.

Prinzing, A., R. Reiffers, W.G. Braakhekke, S.M. Hennekens, O. Tackenberg, W.A. Ozinga et al. 2008. Less lineages - more trait variation:phylogenetically clustered plant communities are functionally morediverse. Ecol. Lett. 11: 809-819.

Purschke O., B.C. Schmid, M.T. Sykes, P. Poschlod, S.G. Michalski, W. Durka et al. 2013. Contrasting changes in taxonomic, phylogenetic and functional diversity during a long-term succession: insights into assembly processes. $J$. Ecol. 101: 857-866.

Ribeiro, M.C., J.P. Metzger, A.C. Martensen, F.J. Ponzoni and M.M. Hirota. 2009. The Brazilian Atlantic Forest: How much is left, and how is the remaining forest distributed? Implications for conservation. Biol. Conserv. 142: 1141-1153.

Ricotta, C. and M. Moretti. 2011. CWM and Rao's quadratic diversity: a unified framework for functional ecology. Oecologia 167: 181-188.

Rozendaal, D.M.A., V.H. Hurtado and L. Poorter. 2006. Plasticity in leaf traits of 38 tropical tree species in response to light; relationships with light demand and adult stature. Funct. Ecol. 20: $207-216$

Scarano, F.R. 2002. Structure, function and floristic relationships of plants communities in stressful habitats marginal to Brazilian Atlantic Rainforest. Ann. Bot. 90: 517-524.
Shooner, S., C. Chisholm and T.J. Davies. 2015. The phylogenetics of succession can guide restoration: an example from abandoned mine sites in the subarctic. J. Appl. Ecol. 52: 1509-1517.

Swenson, N.G. 2013. The assembly of tropical tree communities the advances and shortcomings of phylogenetic and functional trait analyses. Ecography 36: 264-276.

Srivastava, D.S., M.W. Cadotte,A.A.M. MacDonald, R.G. Marushia and N. Mirotchnick. 2012. Phylogenetic diversity and the functioning ofecosystems. Ecol. Lett. 15: 637-648.

Webb, C.O., D.D. Ackerly and S.W. Kembel. 2008. Phylocom: software for the analysis of phylogenetic community structure and character evolution. Bioinformatics 24: 2098-2100.

Webb, C.O. and D.R. Peart. 2000. Habitat associations of trees and seedlings in a Bornean rain forest. J. Ecol. 88: 464-78.

Webb, C.O., D.D. Ackerly, M.A. McPeek and M.J. Donoghue. 2002. Phylogenies and community ecology. Annu. Rev. Ecol. Syst. 33: 475-505.

Weiher, E. and P.A. Keddy. 1999. Ecological Assembly Rules: Perspectives, Advances, Retreats. Cambridge University Press, Cambridge.

Weiher, E., D. Freund, T. Bunton, A. Stefanski, T. Lee and S. Bentivenga. 2011. Advances, challenges and a developing synthesis of ecological community assembly theory. Philos. T. Roy. Soc. B 366: 2403-2413.

Whitfeld, T. J. S., W.J. Kress, D.L. Erickson and G.D. Weiblen. 2012 Change in community phylogenetic structure during tropical forest succession: evidences from New Guinea. Ecography 35: $1-10$.

Received September 18, 2015 Revised May 25, 2016 Accepted June 10, 2016

\section{Supporting information}

Figure S1. The coastal Atlantic Forest and the studied region and the distribution of the 23 forest areas in Southern Brazil.

Figure S2. Scaling up of trait-based data to the community level to reveal trait-convergence and trait-divergence assembly patterns and phylogenetic signal related to ecological gradients.

Table S1. Forest areas analysed in the present study, and their respective reference number, age, local and source.

Table S2. Mantel correlation of the communities sampling size and site localization with diversity.

Table S3. Bibliographic source of plant traits.

The files may be downloaded from www.akademiai.com. 